Gut, 1966, 7, 228

\title{
Chronic gastritis and gastric ulcer
}

\author{
IAN R. MACKAY ${ }^{1}$ AND I. G. HISLOP \\ From the Clinical Research Unit of the Royal Melbourne Hospital and the Walter and \\ Eliza Hall Institute of Medical Research, Melbourne, Victoria, Australia
}

EDITORIAL SYNOPSIS The authors focus attention on the possible role of chronic gastritis as a cause of gastric ulceration and bleeding resulting from decreased mucosal resistance.

Duodenal and gastric antral ulcers differ in certain respects from ulcers in the body of the stomach. Thus with duodenal and gastric antral ulcers there is a high gastric acidity, a large parietal cell mass, and a histologically normal gastric mucosa (Cox, 1952; Ball, 1961), whereas with gastric ulcers there is a normal, low, or even greatly reduced, gastric acid secretion (Levin, Kirsner, Palmer, and Butler, 1948; Morlock and Ratke, 1949; Ball, 1961 ; Baron, 1963), a reduced parietal cell mass, and often a histologically abnormal gastric mucosa with changes of gastritis (Magnus, 1952; Ball and James, 1961). Hence 'decreased mucosal resistance' rather than hyperacidity is claimed to be the important factor in the pathogenesis of gastric ulcer (Illingworth, 1956; Marks and Shay, 1959). This paper describes nine patients in whom gastric ulceration and/or bleeding occurred as a complication of active chronic gastritis: the concept is presented that pre-existing chronic gastritis, in representing one cause of decreased mucosal resistance, is of importance in the pathogenesis of gastric ulceration.

\section{METHODS}

Gastric acid production was assessed by intermittent aspiration of the stomach after an injection of $0.3 \mathrm{mg}$. ('standard' test) or $0.6 \mathrm{mg}$. ('high dosage' test) of histamine (Kay, 1953): the term 'histamine test' denotes the standard test unless otherwise stated. The gastric aspirate was titrated to a $p \mathrm{H}$ of $3 \cdot 5$, using Töpfer's reagent, and the output of acid was expressed as milliequivalents over a 90minute period. ${ }^{3}$ The methods for serum vitamin $B_{12}$ assay and the vitamin $\mathbf{B}_{12}$ absorption and excretion (Schilling) test were as described by Wood, Ralston, Ungar, and Cowling (1964). Serological analyses, including the test for complement-fixing autoantibodies to stomach anti-

'Working with the aid of a grant from the National Health and Medical Research Council of Australia.

${ }^{2}$ Drug Houses of Australia research fellow.

${ }^{3}$ The 90-minute gastric acid production was not measured in test meals before 1956: in these, 'hypochlorhydria' means an acid concentration below $10 \mathrm{mEq}$. per litre in serial specimens of gastric juice. gen, ${ }^{4}$ were as described by Mackay (1964). A blind biopsy from the body of the stomach was obtained with the flexible suction tube (Wood, Doig, Motteram, and Hughes, 1949). Gastritis was defined on the basis of leucocytic infiltration in the gastric mucosa, with or without glandular atrophy, stromal fibrosis and epithelial metaplasia. The gastritis was superficial if there was cellular infiltration without atrophy, atrophic if there was fibrosis and partial loss of specialized cells, active if the leucocytic infiltration was dense, follicular if numerous lymph follicles were present (Magnus, 1952), and patchy if a series of gastric biopsies, or a resected stomach, showed gastritis of varying intensity. Gastric atrophy denoted total loss of specialized cells and minimal leucocytic infiltration. Material aspirated into the biopsy tube during the performance of the biopsy was expelled into a broth medium for aerobic and anaerobic culture, and subculture on blood agar; none of 37 'control' cultures taken at intervals from our gastric biopsy tubes yielded growth of enteric bacteria.

\section{CASE DETAILS}

The details of the cases studied are described briefly below.

CASE 1 A man, aged 62, with recurring pre-antral gastric ulcer and chronic atrophic gastritis for 15 years, in 1947 presented with epigastric pain of 10 years' duration and intermittent vomiting for three years; radiographs showed 'irregularity' of pyloric region and gastroscopy a small pre-antral ulcer which healed in six weeks.

In 1959 abdominal pain and vomiting recurred; gastroscopy showed a pre-antral ulcer; histamine test produced $0.06 \mathrm{mEq}$. of $\mathrm{HCl}$.

In 1960 an ulcer was not demonstrable. A gastric biopsy showed advanced chronic atrophic gastritis with a heavy infiltrate of plasma cells and lymphocytes in the lamina propria and patchy intestinal metaplasia of the epithelial surface (Fig. 1), and a high-dosage histamine test, achlorhydria.

Symptoms recurred in 1961 and a pre-antral ulcer was

'The more sensitive immunofluorescence test for parietal cell antibody was not performed in this study. 


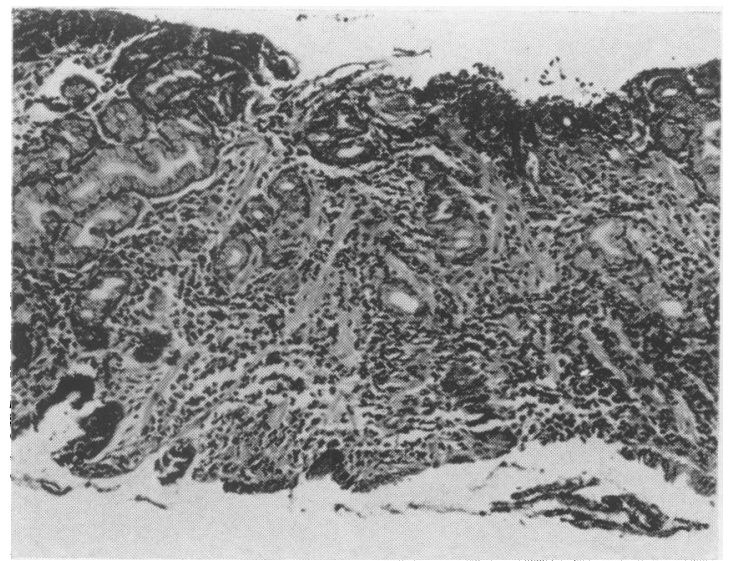

FIG. 1. Representative gastric biopsy from man (case 1) with recurrent gastric ulcer over 15 years: advanced atrophic gastritis. Haematoxylin and eosin $\times 125$.

again demonstrated by gastroscopy and radiographs. A high-dosage histamine test gave $\mathbf{0 . 7 1} \mathrm{mEq}$. of $\mathrm{HCl}$.

From 1961 to 1963 there was no further ulceration; the serum vitamin $B_{12}$ level fell from 290 to $180 \mu \mu \mathrm{g}$. per ml.; five gastric biopsies at intervals showed advanced active atrophic gastritis with lymphoid infiltration and very scanty pepsin-secreting cells.

The patient died in 1963. There was no necropsy but the presumed cause of death, on clinical evidence, was myocardial ischaemia.

CASE 2 A man, aged 61, had persisting atrophic gastritis after healing of acute gastric ulcer. In 1959 he had had 'indigestion' for seven years, haematemesis and melaena for one day. Radiographs and gastroscopy showed a gastric ulcer high on the lesser curvature. A histamine

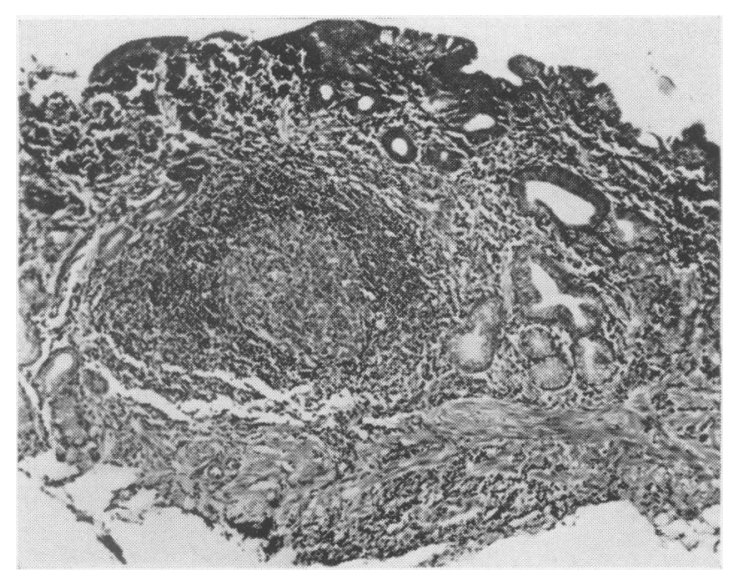

FIG. 3. Gastric biopsy from case 2 obtained three years after healing of ulcer, showing persistence of active atrophic gastritis. Haematoxylin and eosin $\times 90$.

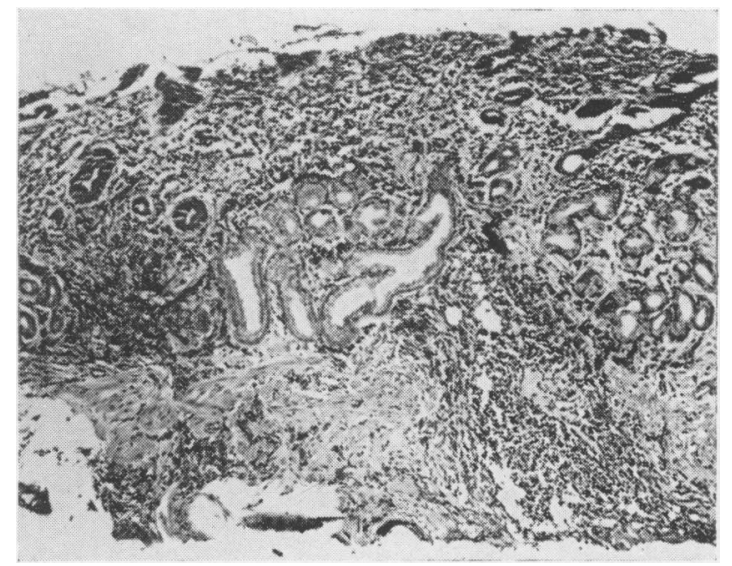

FIG. 2. Gastric biopsy from man (case 2) with gastric ulcer and recent haematemesis; advanced atrophic gastritis and prominent lymphoid follicle. Haematoxylin and eosin $\times 90$.

test showed achlorhydria and gastric biopsy pronounced glandular atrophy with dense lymphoid infiltration (Figure 2). The ulcer healed in three months; no recurrence.

The $\mathrm{HCl}$ output in three histamine tests during 1959-63 ranged from 0.03 to $7.24 \mathrm{mEq}$.; three gastric biposies at intervals showed persisting active atrophic gastritis (Fig. 3), and culture yielded Streptococcus faecalis.

CASE 3 A man, aged 37, with persisting atrophic gastritis and recurrent gastric haemorrhages, in 1949 had mild abdominal pain and haematemesis for five days. A radiograph and gastroscopy were negative; histamine test showed 'hypochlorhydria'. Three gastric biopsies were taken between 1949 and 1951, showing atrophic gastritis with a dense lymphoid infiltration. In 1958-59 he had two gastric bleeds on separate occasions with a recurring small shallow gastric ulcer on the lesser curvature demonstrated by gastroscopy; histamine tests gave 0.73 to $2.28 \mathrm{mEq}$. Three gastric biopsies at intervals all showed severe active atrophic gastritis. In 1959, partial gastrectomy showed an ulcer $3 \mathrm{~mm}$. across on the anterior wall of lesser curvature anteriorly and healed ulcer posteriorly; histology was of widespread atrophic gastritis, lymphoid aggregates, glandular disorganization, numerous eosinophils. Between 1960 and 1964 he had no further haematemeses; histamine test gave $0.15 \mathrm{mEq}$. A gastric biopsy showed persisting atrophic gastritis; serum vitamin $\mathbf{B}_{12}$ level was $170 \mu \mu \mathrm{g}$. per $\mathrm{ml}$.

CASE 4 A man, aged 61, with asthma, had recurrent gastric haemorrhage, gastric ulcer, atrophic gastritis, and early post-gastrectomy vitamin $B_{12}$ deficiency. In 1949 he had had dyspepsia five years and haematemesis five weeks previously. The histamine test showed 'hypochlorhydria' and gastric biopsy patchy atrophic gastritis. In 1954 he had a large melaena but no ulcer was demonstrated. Gastric biopsy showed active atrophic gastritis. In 1956 he had another haematemesis. Radiographs and gastro- 


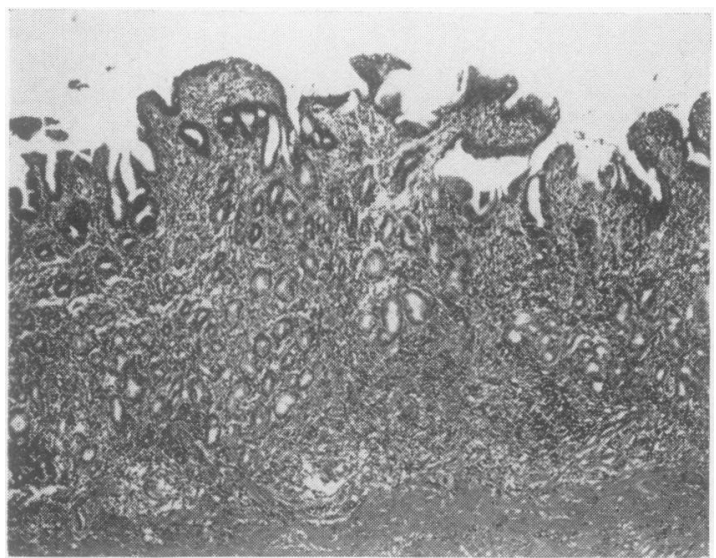

FIG. 4. Section from surgically resected stomach of man (case 4) with recurrent gastric bleeding and gastric ulcer: diffuse atrophic gastritis with heavy lymphoid infiltration. Haematoxylin and eosin $\times 50$.

scopy showed a gastric ulcer high on lesser curvature; histamine test gave $0.33 \mathrm{mEq}$. and gastric biopsy showed advanced atrophic gastritis; later, a perforated gastric ulcer was oversewn. In 1958 after a haematemesis Billroth I gastrectomy was performed; there was an ulcer $1 \mathrm{~mm}$. across on the lesser curvature. Microscopically there was widespread active chronic gastritis (Figure 4). In 1962 the patient had macrocytic anaemia, achlorhydria, advanced gastric atrophy: vitamin $B_{12}, 80 \mu \mu \mathrm{g}$. per ml.; the Schilling test showed grossly impaired $\mathbf{B}_{12}$ absorption, the 48-hour urinary excretion being $4 \%$ of the administered dose.

CASE 5 A woman, aged 48, was addicted to alcohol and phenacetin with atrophic gastritis, haematemeses, and gastric ulcer. In 1960 she had melaena for two days and had had epigastric pains for 10 years. A radiograph and gastroscopy showed a large gastric ulcer on the pars media. A histamine test gave $0.52 \mathrm{mEq}$. of $\mathrm{HCl}$ and gastric biopsy showed atrophic gastritis with large hyperplastic lymph follicle; blood urea was 50 to $66 \mathrm{mg}$. per $100 \mathrm{ml}$. In 1961 she had a haematemesis and Billroth I partial gastrectomy was performed. There was an ulcer $1.5 \mathrm{~cm}$. across proximal to the antrum and microscopically widespread active atrophic gastritis. During 1962-64 she had achlorhydria and advanced atrophic gastritis, with biopsy culture yielding $E$. coli.

CASE 6 A woman, aged 54, had rheumatoid arthritis, Sjögren's kerato-conjunctivitis sicca, atrophic gastritis, and gastric ulcer. In 1951 she had had dry, sore eyes, mouth, and tongue for eight years and arthritis for 20 years. Her mother and brother had pernicious anaemia. Examination showed advanced rheumatoid arthritis and kerato-conjunctivitis sicca. Between 1951 and 1953 a histamine test showed hypochlorhydria and two gastric biopsies mild superficial gastritis. In 1955 she had painful dry eyes and joint pains, and refractory anaemia. Aspirin

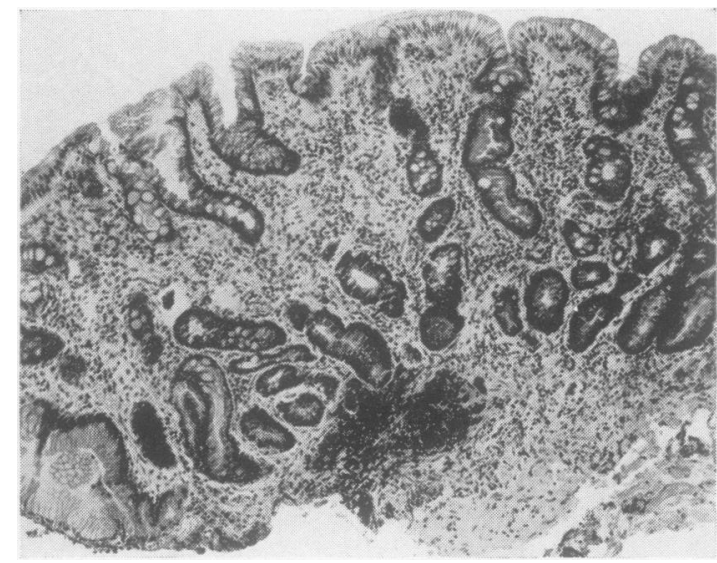

FIG. 5. Gastric biopsy from female (case 6) with Sjögren's disease and gastric ulcer: atrophic gastritis with moderate lymphoid infiltration. Haematoxylin and eosin $\times 90$.

consumption was high. A histamine test showed achlorhydria and gastric biopsy advanced active atrophic gastritis.

Epigastric pain and gastrointestinal bleeding were recurring in 1955-56, and a radiograph showed a gastric ulcer. Histamine tests showed 1.15 and $0.56 \mathrm{mEq}$. of $\mathrm{HCl}$ and a gastric biopsy atrophic gastritis (Figure 5). In 1957 Billroth I partial gastrectomy was performed. A penetrating gastric ulcer $1 \mathrm{~cm}$. across was seen on lesser curvature posteriorly and microscopically there was diffuse advanced atrophic gastritis.

In 1958 necropsy findings were rheumatoid arthritis, atrophic gastritis, fibrous replacement of lacrimal glands, normal salivary and thyroid glands, heavy lymphoid infiltration around tracheal glands, and pyelonephritis with renal papillary necrosis.

CASE 7 A woman, aged 60, had Hashimoto's thyroiditis, chronic hepatitis, atrophic gastritis, and gastric ulcer (reported by Kucers, 1961). In 1958 she had congestive cardiac failure, anaemia, and bleeding gastric ulcer. A thyroid biopsy showed Hashimoto's thyroiditis and liver biopsy active chronic hepatitis with dense lymphoid infiltration. From 1960 to 1963 she suffered from irondeficiency anaemia, hypothyroidism, cardiac failure, and psychosis. A high-dosage histamine test showed achlorhydria. Gastric biopsy was not performed. Three L.E. cell preparations demonstrated 'free-lying material' and numerous 'rosettes' but no classical L.E. cells. In 1963 necropsy findings were Hashimoto's thyroiditis, cirrhosis, healed gastric ulcer in body of stomach, diffuse chronic atrophic gastritis, aggregations of lymphoid cells in renal cortex and in both adrenal glands, and gross thymic atrophy.

CASE 8 A woman, aged 54, had a massive haematemesis, numerous acute gastric ulcers, and follicular gastritis. In 1962 after 'mild indigestion' for 20 years, she had a 


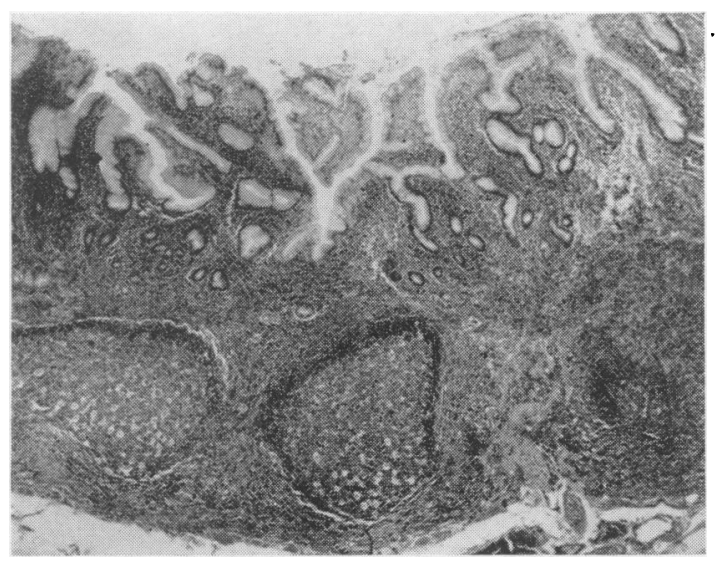

FIG. 6. Section from surgically resected stomach from woman (case 8) with massive haematemesis from multiple acute gastric ulcers: follicular gastritis. Haematoxylin and eosin $\times 75$.

sudden massive haematemesis and melaena. Polya partial gastrectomy was performed when there were numerous small acute gastric ulcers up to $1 \mathrm{~cm}$. across on the anterior wall near the lesser curvature. Microscopically there was diffuse gastritis, numerous lymphoid follicles with germinal centres in the mucosa, and follicular gastritis (Figure 6). In 1964 she had moderate 'dumping', slight macrocytic anaemia (vitamin $\mathrm{B}_{12} 180 \mu \mu \mathrm{g}$. per ml.), achlorhydria on the histamine test. Gastric biopsy showed atrophic gastritis with intense superficial infiltration with plasma cells and some polymorphonuclear cells.

CASE 9 A woman, aged 43, had patchy gastritis and massive gastric bleeding possibly arrested by intravenous prednisolone. In August 1964 after complaining of mild dyspepsia for several years she had gastrointestinal bleeding for two days. Gastroscopy showed a possible shallow gastric ulcer near the antrum. On radiography there was no ulcer in the stomach or duodenum. The histamine test gave $0.50 \mathrm{mEq}$. of $\mathrm{HCl} ; 25$ pints of blood were transfused over 12 days; then prednisolone, $40 \mathrm{mg}$. given intravenously on three occasions over four days was followed by cessation of bleeding. ${ }^{1}$ Gastric biopsy showed patchy atrophic gastritis with moderate plasma cell infiltration. Autoantibody tests were negative. In November 1964 she had slight melaena. A histamine test gave $1.48 \mathrm{mEq}$. of $\mathrm{HCl}$ and gastric biopsy showed patchy superficial gastritis.

SEROLOGICAL TESTS AND BIOPSY CULTURES Case 7 gave positive results to tests for autoantibodies to gastric antigen (titre 1/32), thyroglobulin $(1 / 1,280)$, and cell nuclei; case 6 was not tested and the other cases gave essentially negative results.

\footnotetext{
${ }^{1}$ Although it is appreciated that prednisolone per se may cause gastric ulceration, it was given in this case for its 'anti-inflammatory' effect. We have not as yet had an opportunity to follow up this observation that prednisolone may have caused arrest of massive bleeding associated with gastritis.
}

From case 1 we cultured Streptococcus viridans and a micrococcus from the biopsy aspirate, from case 2 Streptococcus faecalis, and from case $5 \mathrm{E}$. coli. Cases 3,8 , and 9 yielded no growth, and cases 4,6 , and 7 , were not tested.

\section{COMMENTS}

This paper describes nine patients, four men and five women, with chronic or recurrent gastric ulcers, long-standing dyspepsia attributed to chronic gastritis, and often episodes of severe gastric bleeding which necessitated partial gastrectomy in six. All had impairment of acid production in response to histamine stimulation. Serial gastric biopsies showed persisting gastritis characterized by glandular atrophy and disorganization and heavy infiltration of the lamina propria with lymphocytes and plasma cells, occasionally with formation of lymphoid follicles: polymorphonuclear leucocytes were scanty. In one patient, who bled profusely, the stomach showed numerous lymph follicles, as in follicular gastritis (Magnus, 1952).

We considered the possibility that the gastritis in our patients was of the 'zonal' type which is localized to the vicinity of, and perhaps secondary to, a gastric ulcer (Magnus, 1952; Joske, Finckh, and Wood, 1955; Card and Sircus, 1958); however serial gastric biopsies showed that the gastritis persisted despite healing of the ulcer, and gastrectomy specimens in six cases showed the gastritis to be widespread. Moreover Magnus (1952) found that gastritis, often severe in degree with much destruction of gland parenchyma, was present in all of 284 partial gastrectomy specimens removed for gastric ulcer, and this gastritis was diffuse in $26.5 \%$ of the cases.

It is our concept that active chronic atrophic gastritis represents the state of 'decreased mucosal resistance' or 'vulnerability' which is believed to predispose to gastric ulceration (Illingworth, 1956; Kirsner, Clayman, and Palmer, 1959). We would not, of course, exclude a contributory rôle of acid-peptic activity since, in all of our cases, there was some degree of gastric acidity, albeit reduced, and highdosage histamine stimulation tests occasionally yielded moderate amounts of acid. The biopsy features of the present cases would indicate that ulceration occurs in the active 'inflammatory' type of chronic gastritis, which may be patchy $a b$ initio, rather than in the relatively acellular type usually associated with pernicious anaemia, as implied by Washburn and Rozendaal (1938).

The causes of gastritis include dietary irritants, malnutrition, alcohol, and drugs such as aspirin, but the basic pathogenesis of the persisting damage of chronic atrophic gastritis is unknown. The histo- 
logical appearance of the stomach in our cases was indicative of an immunological response in the wall of the stomach, and we were interested in the cause(s) of this response and their relationship, if any, to the actual cause(s) of the mucosal damage. One factor considered was chronic infection with enteric bacteria, perhaps facilitated by hypochlorhydria, impaired secretion of mucus, or other undetermined predisposing factors; bacteria were isolated from the stomach in our cases 1,2, and 5. Another factor could have been autoimmune reactivity, since the chronic atrophic gastritis of pernicious anaemia is associated with serological evidence of autoimmunity to gastric parietal cells (Taylor, Roitt, Doniach, Couchman, and Shapland, 1962; Irvine, Davies, Delamore, and Williams, 1962; Mackay, 1964). It is likely that the autoimmune reaction is the cause, rather than merely a result, of this chronic atrophic gastritis, since, in the comparable damage of post-gastrectomy gastritis, the incidence of parietal cell antibody is low (te Velde, Abels, Anders, Arends, Hoedemaeker, and Nieweg, 1964). In relation to an autoimmune pathogenesis, case 6 had Sjögren's disease and rheumatoid arthritis, and case 7 had Hashimoto's disease, chronic hepatitis, and complement-fixing antibodies to stomach mucosal antigen to a titre of $1 / 32$. We were also interested to note that Doniach and Roitt (1964) reported a raised incidence of parietal cell antibodies in gastric ulcer $(22 \%)$, but not in duodenal ulcer. However, we would emphasize that in four of our cases we obtained no hint of the cause of the immune response in the stomach nor of the associated mucosal damage.

Our findings suggest that there is a limited group of cases where an established gastritis is followed by gastric ulceration. If the gastritis were initially patchy with mucosal breakdown in one of the involved areas, the more normal areas would be adequate to secrete acid and pepsin which would aggravate and cause persistence of the ulcer. Later the gastritis may become diffuse and involve the entire stomach with depleted acid and pepsin secretion, and yet the ulcer may not heal if the basic pathogenic process responsible for the gastritis persists, be this an extrinsic damaging agent or an autoimmune reaction.

The significance of chronic atrophic gastritis as a disease process was emphasized by Wood and Taft (1958) and by Wood et al. (1964). First, of 221 cases with chronic atrophic gastritis studied in our Unit, $40 \%$ suffered from dyspepsia attributable entirely or in part to the gastritis (Wood and Taft, 1958), and chronic gastritis was present in $19 \%$ of 200 patients with dyspepsia reported by Coghill (1960): however, some authors are not convinced that gastritis is a cause of symptoms (Coghill, 1960). Secondly, atrophic gastritis is the basic histological lesion of adult pernicious anaemia, but it is uncertain whether 'simple' atrophic gastritis inevitably progresses to the gastritis of pernicious anaemia (Williams, Coghill, and Edwards, 1958; Whiteside, Mollin, Coghill, Wynn Williams, and Anderson, 1964): perhaps an additional factor is necessary, i.e., a genetically determined predisposition to form autoantibody to intrinsic factor or parietal cell antigen. Thirdly, chronic gastritis may predispose to the development of gastric carcinoma, although this is unproven. Fourthly, chronic gastritis, as suggested by our findings and those of others (Langman, Hansky, Drury, and Avery Jones, 1964), may be an important determinant of gastric ulceration and bleeding.

\section{SUMMARY}

In nine patients a persisting active chronic atrophic gastritis was associated with recurrent or chronic gastric ulceration, often with bleeding. The gastritis was widespread, and persisted or progressed despite healing of the ulcer. Histologically the gastric mucosa showed glandular atrophy, heavy lymphocyte-plasma cell infiltration, and, frequently, lymphoid follicles, indicative of a sustained immune reaction. These appearances may have been related to bacterial infection or autoimmunity in five of our nine cases: no clear hint as to causation was obtained in the remaining four. We suggest that chronic atrophic gastritis may be an important determinant of gastric ulceration and bleeding.

The vitamin $B_{12}$ estimations were performed by Dr. D. C. Cowling and Dr. Berta Ungar of the Clinical Pathology Department, Royal Melbourne Hospital. Mr. E. Matthaei, of the University of Melbourne, prepared the photomicrographs. Case 7 was studied through the courtesy of Dr. J. L. Frew.

\section{REFERENCES}

Ball, P. A. J. (1961). The secretory background to gastric ulcer. Lancet, 1, 1363-1365.

- and James, A. H. (1961). The histological background to gastric ulcer. Ibid., 1, 1365-1367.

Baron, J. H. (1963). An assessment of the augmented histamine test in the diagnosis of peptic ulcer. Gut, 4, 243-253.

Card, W. I., and Sircus, W. (1958). Anacidity. In Modern Trends in Gastroenterology, edited by F. Avery Jones, 2nd series, pp. 177-192. Butterworth, London.

Coghill, N. F. (1960). The significance of gastritis. Postgrad. med. J., 36, 733-742.

Cox, A. J., Jr. (1952). Stomach size and its relation to chronic peptic ulcer. Arch. Path., 54, 407-422.

Doniach, D., and Roitt, I. M. (1964). An evaluation of gastric and thyroid auto-immunity in relation to hematologic disorders. Seminars Hemat., 1, 313-343.

Illingworth, C. F. W. (1956). Inborn and extraneous factors in the aetiology of peptic ulcer. J. roy. Coll. Surg. Edinb., 2, 14-23.

Irvine, W. J., Davies, S. H., Delamore, I. W., and Williams, A. W. (1962). Immunological relationship between pernicious anaemia and thyroid disease. Brit. med. J., 2, 454-456. 
Joske, R. A., Finckh, E. S., and Wood, I. J. (1955). Gastric biopsy: a study of 1000 consecutive successful gastric biopsies. Quart. J. Med., 24, 269-294.

Kay, A. W. (1953). Effect of large doses of histamine on gastric secretion of $\mathrm{HCl}$ : an augmented histamine test. Brit. med. J., 2, 77-80.

Kirsner, J. B., Clayman, C. B., and Palmer, W. L. (1959). The problem of gastric ulcer. Arch. intern. Med., 104, 995-1020.

Kucers, A. (1961). Autoimmune thyroiditis and hepatitis in a patient with gastric ulcer. Med. J. Aust., 1, 325-326.

Langman, M. J. S., Hansky, J. H., Drury, R. A. B., and Jones, F. Avery (1964). The gastric mucosa in radiologically negative acute gastrointestinal bleeding. Gut, 5, 550-552.

Levin, E., Kirsner, J. B., Palmer, W. L., and Butler, C. (1948). Nocturnal gastric secretion: studies on normal subjects and on patients with duodenal ulcer, gastric ulcer, and gastric carcinoma. Arch. Surg., 56, 345-356.

Mackay, I. R. (1964). Autoimmune serological studies in chronic gastritis and pernicious anaemia. Gut, 5, 23-26.

Magnus, H. A. (1952). Gastritis. In Modern Trends in Gastroenterology, edited by F. Avery Jones, 1st series, pp. 323-351. Butterworth, London.

Marks, I. N., and Shay, H. (1959). Observations on the pathogenesis of gastric ulcer. Lancet, 1, 1107-1111.

Morlock, C. G., and Ratke, H. V. (1949). Gastric ulcer in the presence of histamine achlorhydria. Gastroenterology, 13, 241-245.
Taylor, K. B., Roitt, I. M., Doniach, D., Couchman, K. G., and Shapland, C. (1962). Autoimmune phenomena in pernicious anaemia: gastric antibodies. Brit. med. J., 2, 1347-1352.

te Velde, K., Abels, J., Anders, G. J. P. A., Arends, A., Hoedemaeker, P. J., and Nieweg, H. O. (1964). A family study of pernicious anaemia by an immunologic method. J. Lab. clin. Med., 64, 177-187.

Washburn, R. N., and Rozendaal, H. M. (1938). Gastric lesions associated with pernicious anemia. Ann. intern. Med., 11, 2172-2180.

Whiteside, M. G., Mollin, D. L., Coghill, N. F., Wynn Williams, A., and Anderson, B. (1964). The absorption of radioactive vitamin $B_{12}$ and the secretion of hydrochloric acid in patients with atrophic gastritis. Gut, 5, 385-399.

Williams, A. W., Coghill, N. F., and Edwards, F. (1958). The gastric mucosa in pernicious anaemia : biopsy studies. Brit. J. Haemat., $4,457-464$.

Wood, I. J., Doig, R. K., Motteram, R., and Hughes, A. (1949). Gastric biopsy: report on 55 biopsies using a new flexible gastric biopsy tube. Lancet, 1, 18-21.

—, Ralston, M., Ungar, B., and Cowling, D. C. (1964). Vitamin $B_{13}$ deficiency in chronic gastritis. Gut, 2, 27-37.

- , and Taft, L. I. (1958). Diffuse Lesions of the Stomach. Arnold, London. 